\section{reply to Griffin}

I am happy to take note of the information sent along by Professor Griffin. It is interesting to learn that the Principle of Charity has been enunciated in other contexts - e.g., as a rule for translators proposed by Wilson. However, I am mainly interested in its use by informal logicians as a principle of argument analysis. It is clear that such is not the use to which Wilson's principle is geared. Hence I would like to amend my original assertion to read: "So far as I am aware, the first mention of this principle as a principle of argument analysis is to be found in Thomas's ..."

Ralph Johnson

\section{teaching note}

\section{A System of Rational Appraisal}

\section{Robert Binkley University of Western Ontario}

\section{editors's note}

A couple of years ago, Professor Robert Binkley shipped us a bundle of material from a logic course he was teaching at the time. We've dug out yet another useful item from that bundle: his graphic for his "System of Rational Appraisal." We've added a few comments of our own.

1. System of rational appraisal. The flow chart above the cartoon represents the whole appraisal system in broad strokes. The first four boxes - Discourse, Surface Analysis, Classified Non-argument and Representation of Surface Structure - are spelled out in fuller detail on the second page, in the "Surface Analysis Flow Chart" (see below).
To us the most striking feature of this chart is its distinction between "surface analysis" and "depth analysis". We may have it wrong, but we take this to refer to the distinction between what someone's discourse may be made out to mean when taken literally, or better, when the person is taken at his word (which may certainly allow and call for interpretation), and what we may safely infer the person's underlying or deeper message is. Irony and sarcasm are perhaps the clearest examples of discourse whose meaning may be missed by a surface analysis. Humour is another.

A "surface" argument may be so wildly illogical that literal interpretation would be not only uncharitable, but stupid: such illogic could only be the product of wit; hence the need for depth analysis and its verdict: "No serious argument intended here. It's a joke." (Without this distinction Binkley's cartoon would be seen as an example of a logical fallacy. So it's vital.)

The unclosed side-boxes - "Charity, Fidelity and Discrimination" and "Relevance, Sufficiency and Acceptability" - merit glosses.

By "Charity" and "Fidelity", we presume that Binkley was referring to the Principles of Charity and Fidelity found in, among other places, Scriven's Reasoning. The Principle of Fidelity means that the critic must be faithful to the original argument; the Principle of Charity requires that one provide the best possible interpretation of the argument; and the Principle of Discrimination (though not explicity so referred to by Scriven) requires the critic to "go to the heart of the matter", i.e., give prominence to the strongest criticisms and not nitpick or waste time on minor points.

About "Relevance", "Sufficiency", and "Acceptability", since they come from our text, we can add this: we hold in Logical Self-Defense that in a logically good argument the premises are relevant to the conclusion, together they provide sufficient support for the conclusion, and each must be worthy of acceptance by the audience of the argument.

2. Surface Analysis Flow Chart. This is pretty selfexplanatory, but we have one comment of explanation and one caveat. At the bottom of the chart the path of analysis branches, going to either "Draw Diagram" or "Standardize", or to both. By "diagram" we believe Binkley had in mind tree diagrams of argument structure such as those used in Scriven's Reasoning and Thomas's Practical Reasoning in Natural Language. By "standardize" he is referring to the system introduced in Logical Self-Defense consisting of writing the premises above the conclusion they are put forward to support, and numbering them for convenience of reference (P1, P2, P3, etc.). The point of making the two alternative argument-structuring methods available is that tree-diagramming is easier and more perspicuous for longer and more complicated arguments, standardizations can be made immediately for simpler arguments, and a standardization can be written up off a tree diagram. (Metanote: We have come to think the standardizing tech- 
System of Rational Appraisal
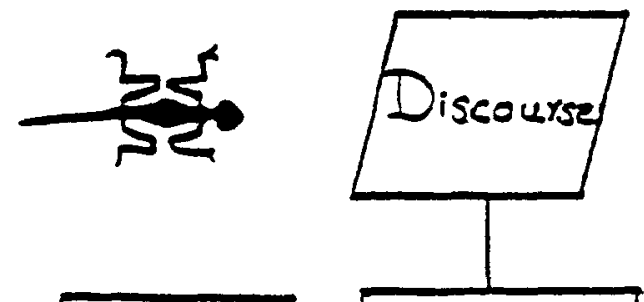

Classified Non-arguraen $\leftarrow$ Arralysis

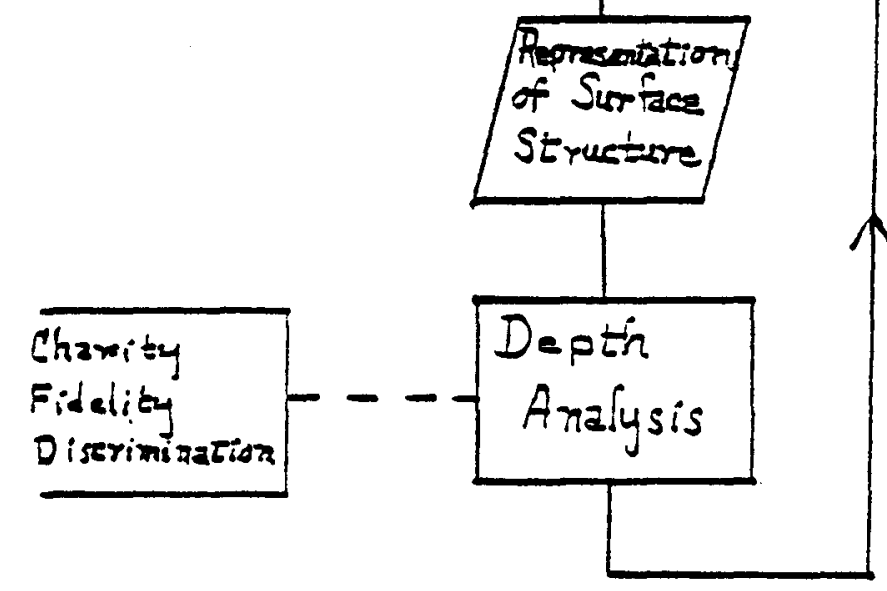

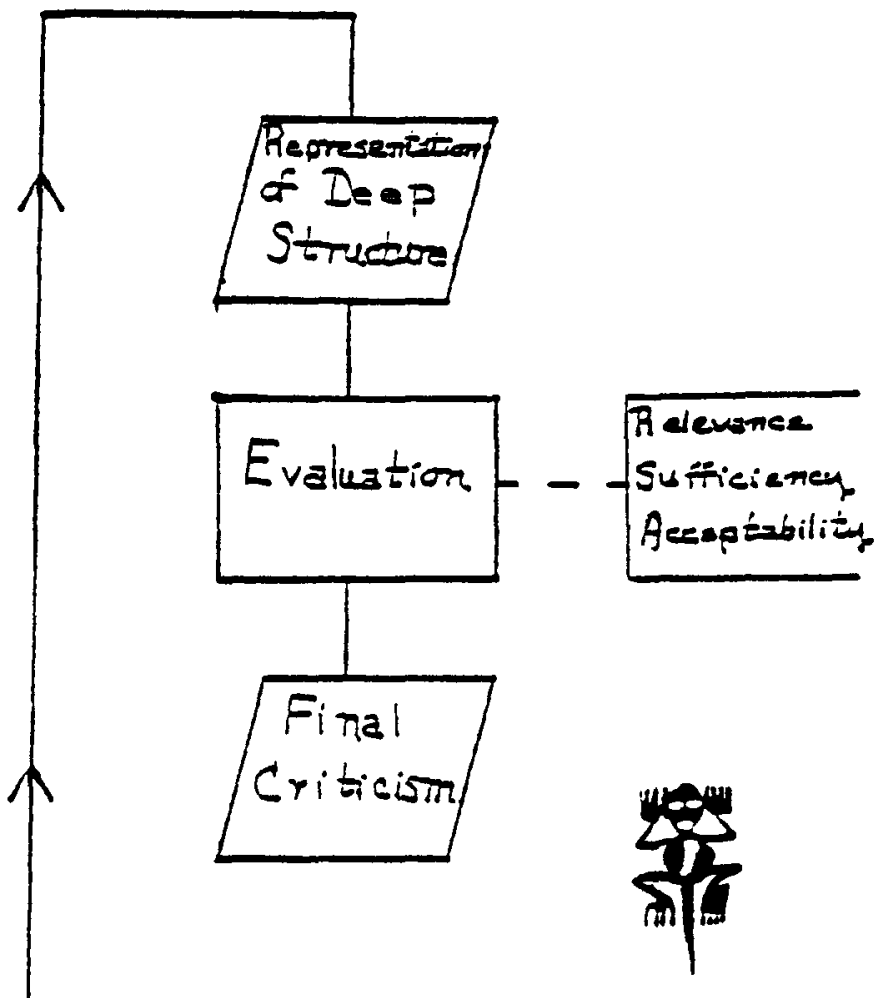

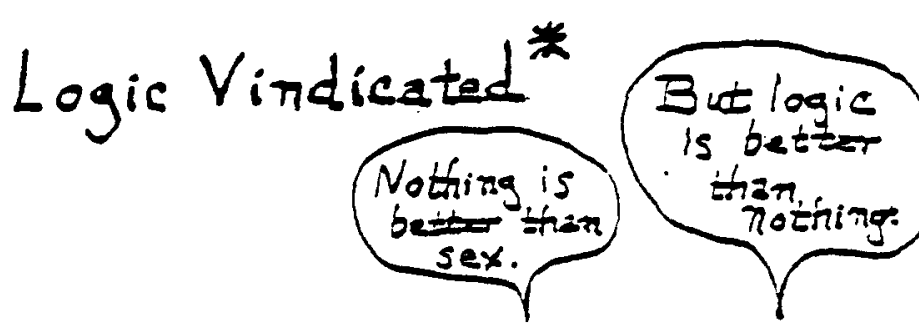

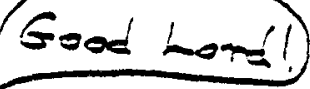

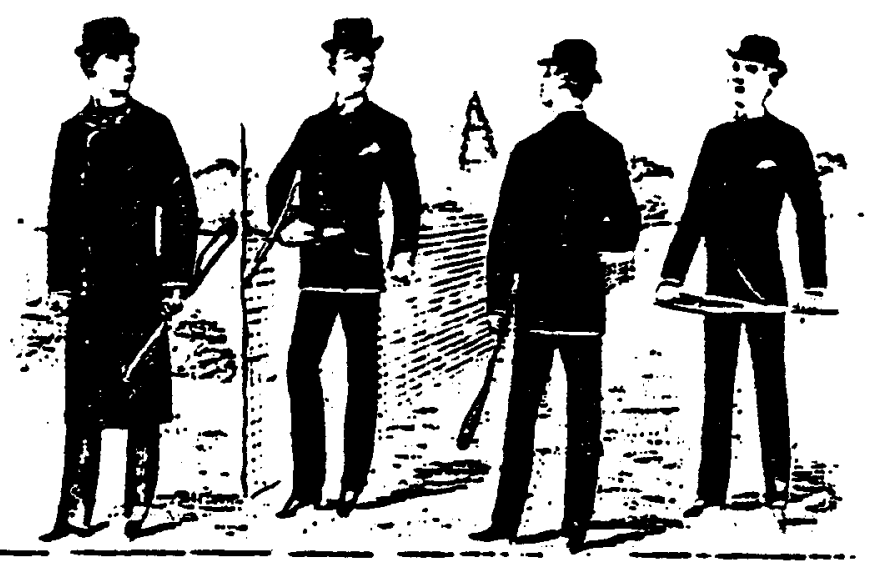

* Niblapologies to in honourabie member of ine dass. 
Surface Aralysis Flow Chart

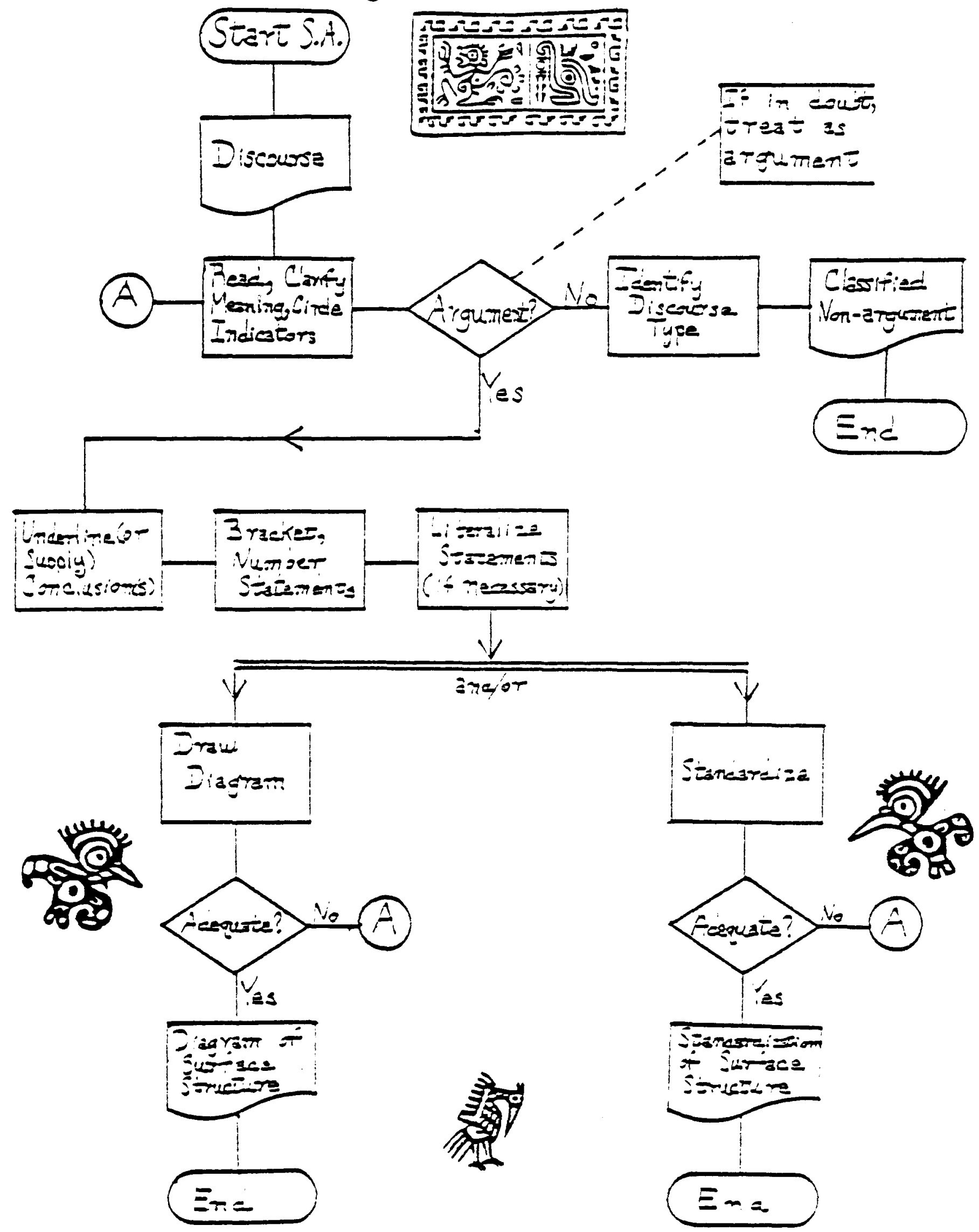


nique is too cumbersome; this undermines the benefits of its convenience to the reader.)

Our caveat is this. Lately it has been striking us that much of the discourse that has a persuasive turn or flavour and that we have been presenting to our students as arguments to be analyzed, in fact may not have the credentials of pondered, organized and backed-up thought which should be demanded of discourse before it is honoured by the application of careful, serious, probing - such as Binkley's chart provides for. Hence we are not sure whether Binkley's advice: "Argument? If in doubt, treat as argument" should be followed. (This caveat opens a bit of a Pandora's Box, by the way. Much, if not most, of daily discourse, both unrecorded and reproduced in the media, is at best proto-, or pseudo-, or semi-argumentation. If it should not be analyzed as if it were argumentation, should it not be analyzed at all? Should all that persuasive discourse be allowed to flow by without any critical scrutiny? If it merits assessment, but the tools of argument analysis should not be those used, then how is it to be evaluated? What is it, if not argument? Furthermore, if informal-fallacy analysis is one's favoured tool of criticism, and fallacies are flaws in arguments, then whither fallacy analysis? Or, is this quasi-argumentation just the true domain of fallacy analysis?)

\section{conference notice}

AAPT

The American Association of Philosophy Teachers will sponsor the Fourth National Conference-Workshop on Teaching Philosophy. The conference will be held at Appalachian State University in Boone, North Carolina, between August 4-8, 1982. A wide variety of workshops having to do with teaching philosophy will be offered. Among the areas to be covered are: philosophy for children, philosophy in high schools, two-year college philosophy, introductory philosophy, logic, informal logic, logic with computers, ethics, bioethics, business ethics, professional ethics, applied philosophy, philosophy and computers, death and dying, feminism, films, publishing on teaching, improving lecturing or discussion skills, teaching techniques, and ANYTHING else imaginative, innovative and interesting.

A special feature of the Fourth National ConferenceWorkshop on Teaching Philosophy will be a Plenary Session on "Evaluating Philosophy Teaching," which will raise questions and offer insights into what it is teaching philosophy aims to do and how to determine success and failure in reaching our goals.
Second International Symposium on Informal Logic

A reminder that the Second International Symposium on Informal Logic is scheduled for June 20-23, 1983 at the University of Windsor (Windsor, Ontario, Canada).

The program will cover theory and teaching of informal logic/critical thinking. It is time to start thinking about that paper you would like to submit for the program. And it's none too soon to mark the date on your calendar and clear the time (and funds) to be able to attend. Convenors: Blair \& Johnson.

Copies of the proceedings of the First International Symposium - Informal Logic - are still available from Edgepress, Box 69, Point Reyes, California 94956 for $\$ 9.95$ plus $\$ .55$ postage (California residents add state tax of $\$ .60)$

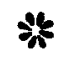

\section{announcement}

\author{
An Informal Logic Workbook
}

The project to assemble a collection of examples into a workbook that can be used by instructors and students for teaching and learning reasoning skills was completed in August. Kate Parr (M.A., Windsor 1981) ran the project and wrote and edited a lot of the Workbook. Material and analyses were collected and produced by alumni of Windsor's informal logic course: Frank Carlone, Karol Dycha and Leo Raffin. Joyce Mussio typed and retyped drafts all summer.

The Workbook runs to 97 pages, and is divided roughly into three parts. The first part uses examples and succinct advice designed to help learn how to detect arguments, restate rhetorical questions, identify missing conclusions, do tree diagrams of argument structure, and identify missing premises. There are 66 examples in this part, half of which have answers provided by the authors. The second part is a roster of arguments which contain informal fallacies. There are 44 examples here, and the authors provide their own critiques of all the examples in this section. The third part consists of 33 unanalyzed arguments, most of which, the authors believe, contain fallacies. At the back of the Workbook there is an alphabetical guide to common fallacy names, and a collection of the defining conditions of 24 common fallacies taken from Johnson and Blair's Logical Self-Defense. An index to the fallacies in the third part is available to instructors only.

The Workbook was designed by students as a learning aid for students as well as a teaching aid and source of 